Удк 316.325:004.738.5

\title{
SMART SOCIETY: ПОДХОДЫ И ИНТЕРПРЕТАЦИИ
}

\author{
Нетесова Мария Витальевна1,2, \\ Netesova@tpu.ru \\ 1 Томский государственный педагогический университет, \\ Россия, 634061, г. Томск, ул. Киевская, 60а \\ 2 Национальный исследовательский Томский политехнический университет, \\ Россия, 634050, г. Томск, пр. Ленина, 30
}

\begin{abstract}
Нетесова Мария Витальевна, старший преподаватель кафедры перевода и переводоведения Томского государственного педагогического университета; аспирант отделения социальногуманитарных наук Школы базовой инженерной подготовки Национального исследовательского Томского политехнического университета.
\end{abstract}

Актуальность обусловлена текущими процессами трансформации общества, развивающегося соответственно применению современных технологий. Рассматриваются ключевые характеристики концепции smart society (смарт-общество), которые являются недавней концепцией в качестве руководства для социального развития, и могут оказать глубокое воздействие на общество на всех уровнях, например с точки зрения качества жизни и устойчивости. Цель - на основе имеющихся исследований по тематике работы выявить наиболее распространенные концепции, интерпретирующие феномен «sтаrt society» и его ключевые характеристики. Методы: общенаучные и философские методы исследования, среди которых логико-аналитический (при выстраивании логики исследования), метод теоретического анализа литературы по теме с возможностью логического и сравнительного анализа изученных данных, аналитический и компаративный методы, позволившие применить междисциплинарный подход к изучению дефиниций «smart society» $u$ «smartnеss» (разумность). Результаты: приводятся интерпретации феномена smart society. Разрабатываются определения «умный» и «общество». Рассматриваются концепции зарубежных ученых, таких как Юко Харайма (Япония), Томас Кристиан Бёхле (Германия), Татео Аримото (Германия), Митчел Дин (США), Мэтью Глэдден (Польша) Лорена Батаган (Турция), Джоанна Брайсон (Германия), Александра Медина Борджа (Бразилия), Ари-Вейко Антиройко (Финляндия) и пр., чьи научные изыскания посвящены всевозможным вопросам, связанным с развитием smart society. Выявлены ключевые характеристики «sтаrtness» (разумности), а также характеристики современного smart society непосредственно. Smartness pacсматривается относительно каждого компонента общества (политическая сфера, государственное управление, сферы услуг, экономическая деятельность, образовательная деятельность). Выделяются своего рода «движущие силы» развития smart society. Обзорно представлены существующие зарубежные программы-практики («Умная Япония», «Умный Таиланд 2020», «Умная Африка», «Умная Великобритания»), целью которых является создание smart society.

Ключевые слова: Smart society, смарт-общество, умное общество, smartness, разумность.

\section{Введение}

Цифровизация общества, политики и экономики оказывает влияние на основы всех сфер жизнедеятельности. Какую модель общества получит человечество в результате повсеместного развития и применения автоматизации и алгоритмической обработки данных? Как будет выглядеть такое цифровое общество? Какие теории и концепции помогут человеку осмыслить и принять или не принять эту трансформацию и в какой 
степени дискурсы формируют и объясняют ее? Какую роль играют новые сетевые устройства и технологии, которые стали естественной частью материальных структур нашей повседневной жизни и опыта?

Все эти вопросы, глубоко касающиеся отличительных черт цифровых обществ, являются фундаментальными и представляют масштабную проблему для исследователей. Эмпирические исследования могут дать только ограниченные ответы, поскольку они в основном сосредоточены на четко определенных аспектах гораздо более крупных явлений. Однако трудно обнаружить и объяснить долгосрочные и всеобъемлющие изменения. Кроме того, неясно, способны ли превалирующие концепции и теории уловить текущие преобразования и формирующееся цифровое общество вообще.

Нынешние быстрые социальные и технологические изменения приводят к огромной неопределенности - для человека возрастает необходимость объяснения и осмысления текущих процессов и трансформаций, а также нашего общего будущего. Возникает необходимость разобраться в реальных изменениях, которые происходят в обществе за пределами ажиотажа и в погоне за повсеместным внедрением смарттехнологий.

\section{Умное общество - подходы и интерпретации}

Smart society («Умное общество», или «Умная нация», или «Общество 5.0») - широко использующийся термин для обозначения видения будущего плана региона, страны, нации, человечества в целом по созданию передового информационного общества.

Системы и услуги информационно-коммуникационных технологий (ИКТ) стали важными компонентами развития многих аспектов жизни - так или иначе будущий прогресс в области культуры, образования, здравоохранения, сельского хозяйства, транспорта и торговли достигается с помощью систем и услуг ИКТ. Умное управление автомобильным движением, экономия электроэнергии, измерение воздействия загрязнения окружающей среды, повышение урожайности в сельском хозяйстве, управление здравоохранением и образованием, управление и контроль снабжения питьевой водой, решение проблем, с которыми сталкиваются города и сельские районы - все это далеко не полный список операций, которые совершаются людьми ежедневно, при помощи применения ИКТ. Сегодня ИКТ играют ключевую роль в защите собственности и людей. Таким образом, мир постепенно прогрессирует до «умного общества». Выполнение обещаний «Smart society» основывается на трех технологических элементах: подключаемости, интеллектуальных устройствах и программном обеспечении, а также принципах устойчивого развития [1].

«Smart society», или «умное общество», состоит из «умного» и «общества», поэтому определение умного общества требует от нас понимания природы «умного», а также сферы или характеристик «общества».

Слово «умный» очень широко используется в терминах «умный телефон», «умный автомобиль», «умный дом», «умное здание», «умное сельское хозяйство», «умная школа (обучение)», «умный город» и «умное общество». В случае словосочетаний «умный автомобиль», «умный дом», «умное здание» и «умное сельское хозяйство» слово «умный» означает, что автомобиль, дом, здание и сельскохозяйственный объект выполняют свои функции автономно с помощью технологий программирования или искусственного интеллекта без применения ручных манипуляций владельца. Но если подумать над словосочетанием «умная школа или обучение», субъект, выполняющий автономную функцию, это не вещь, а человек (студент), и, следовательно, это означает, что он учится самостоятельно с помощью интеллектуальных устройств и в среде «ум- 
ной школы». Понятия «город» и «общество» включают в себя своего рода субэлементы: управление, граждане, образ жизни и т. д. Поэтому чтобы город или общество назывались «умными», его управление, граждане и образ жизни должны быть разумными.

Общество - это своего рода проблемное единство людей, которому присущи общие интересы, это единство может иметь особую культуру и институты. Общество может относиться к определенной этнической группе, к национальному государству или к более широкой культурной группе, например западное общество [2]. В обществе люди объединены в религиозных, благотворительных, культурных, научных, политических, патриотических или иных целях. Люди объединяются в общество под действием внешних и внутренних угроз населению и территории государства, по экономическим причинам. Австралийский профессор социологии Митчел Дин пишет о том, что общество должно бороться с дезинтегративными силами конфликта и неравенства, поскольку оно стремится интегрировать свое разнообразное население в капиталистическую экономику и либеральный правовой и политический порядок [3, с. 691].

Smart society - это общество, которое опирается на силу и потенциал технологий, чтобы сделать людей более продуктивными; позволить нам сосредоточить наши ресурсы на деятельности и отношениях, которые имеют значение; в конечном итоге для улучшения здоровья, благополучия и качества жизни. Smart society - своего рода новый этап в периодизации истории, где общество уделяет особое внимание применению смарт-технологий для реализации потребностей человека в этом обществе [4, с. 44]. Группа технологических достижений меняет то, как люди живут, работают и играют. Физические и виртуальные области нашей жизни все больше переплетаются. Все больше и больше наших взаимодействий обеспечивается машинами. Интернет вещей (IoT), M2M (Machine-to-Machine), гиперподключаемость, носимые технологии, интеллектуальная жизнь и повсеместные вычисления становятся все более важными областями [5].

По мнению британского писателя, политика и лидера общественного мнения Британии Чарльза Ледбитера, умное общество (smart society) - это общество, которое генерирует и использует знания, чтобы быть более успешным [6].

В 2017 г. была опубликована статья «The "Smart Society" of the Future Doesn't Look Like Science Fiction» - «Умное общество будущего не кажется научной фантастикой» [7]. Авторы - Бхаскара Чакраворти (декан факультета глобального бизнеса в Школе Флетчера, Университет Тафтса, США, штат Массачусетс, основатель и исполнительный директор Института бизнеса Флетчера в глобальном контексте, автор «Медленного темпа быстрых перемен») и Рави Шанкара Чатурведи (младший директор по исследованиям, докторант по инновациям и изменениям в Институте бизнеса Флетчера в глобальном контексте при Университете Тафтса). В данной статье smart society определено как общество, в котором цифровые технологии, продуманно внедренные правительствами, могут улучшить три основных результата: благосостояние граждан, прочность экономики и эффективность институтов [7].

Авторы зарубежных работ, посвященных развитию smart society и философскому анализу трансформация обществ, нередко используют термин «Society 5.0». Они отмечают тот факт, что по сути Общество 5.0, или Супер умное общество, стремится использовать быстро развивающиеся технологии для производства в рамках предприятия и более глубоко интегрировать их в повседневную жизнь простых людей. Внедрение смарт-технологий ведет к повышению эффективности, результативности и повышению финансовых показателей предприятий. Это своего рода коммерческий акцент в приме- 
нении смарт-технологий, но задача Супер умного общества - установление равновесия путем внедрения технологий, связанных с социальной робототехникой, Интернетом вещей, окружающим интеллектом, которые дополняют и виртуальную реальность, и передовые человеко-компьютерные интерфейсы для качественного улучшения жизни человека на благо общества в целом [8].

В частности, Карлос Мигель и Сандро Серпа утверждают, что углубление потенциала индивидуально-технологических отношений приведет к улучшению качества жизни всех людей через сверхинтеллектуальное общество [9]. Эту идею они предлагают использовать в качестве концепции руководства для социального развития, и это может оказать глубокое влияние на общество, касательно вопросов условий качества жизни и устойчивости. Бразильские ученые в 2017 г. предположили, что технологии Общества 5.0 не просто обеспечат минимум услуг, необходимых для выживания людей, но будут работать на то, чтобы сделать жизнь более значимой и приятной; взаимодействие человека и технологии будет использовано для «обеспечения устойчивого, яркого, пригодного для жизни, ориентированного на людей мир» [10]. Подобная идея была выдвинута чуть ранее, в 2016 г., японским исследователем Татео Аримото. Он отмечает, что в обществе 5.0 различные потребности общества тонко дифференцированы и удовлетворяются путем предоставления необходимых продуктов и услуг в необходимых количествах нуждающимся людям, тогда и когда это необходимо. Smart society позволяет всем людям без исключения получать высококачественные услуги и жить комфортной, энергичной жизнью, которая учитывает различия этих людей, такие как возраст, пол, национальность, принадлежность к той или иной религии или конфессии и другие, но не ущемляет [11].

Несколько работ, посвященных вопросам развития smart society, или Общества 5.0, принадлежит Мэтью Глэддену [12]. Его исследования посвящены анализу влияния технологической постгуманизации на то, как современное общество структурирует организации, социальное взаимодействие и архитектуру пространств, в которых мы живем. К таким сферам относятся не только физические пространства зданий и рабочих мест, но также когнитивные, информационные и экспериментальные пространства, как «реальные», так и виртуальные.

Олег Смолин (доктор философских наук, академик Российской академии образования) считает, что на пути построения smart society необходимо решить две задачи. Первая - суметь применить современные технологии. Вторая - применить их так, чтобы они служили в интересах общества и человека, а не против них [13]. Человек должен господствовать над технологиями в современности, как в свое время человек, по мнению Фрэнсиса Бэкона, должен был господствовать над животным миром [14].

\section{Smart society - характеристики разумности}

В 2014 г. состоялась Всемирная конференция по развитию телекоммуникаций и связи «World Telecommunication Development Conference - WTDC-14», в рамках которой участники попытались определить, что такое smartness (разумность) и что должно быть включено в границы умного общества [15].

Итак, выделяют следующие характеристики разумности относительно smart society, которое ориентировано на разумное производство и предоставление услуг:

1) внедрение автономной работы посредством сенсорных технологий;

2) внедрение искусственного интеллекта с помощью технологии машинного обучения; 
3) предоставление повсеместных услуг в любое время и в любом месте с помощью мобильных технологий;

4) предоставление ориентированных на пользователя услуг через постоянную связь между поставщиками и потребителями [15].

Заключительный элемент - предоставление ориентированных на пользователей услуг посредством постоянной коммуникации между поставщиками и потребителями представляется наиболее важным для наделения общества таким качеством, как smartness (разумность). Разумность выступает в данном случае обязательной характеристикой каждого компонента smart society.

Общество - непосредственный творец и участник политической, культурной, образовательной и экономической сфер деятельности, государственного управления, сервисов и т. д. Понятие smartness может быть применено для каждого компонента общества. Так, если говорить о политической сфере деятельности, умное общество - это то общество, в котором граждане принимают активное участие в формировании политики, законотворчестве. Smart society гарантирует открытость законов и политических процессов.

Государственное управление и служба в smart society подразумевают активное участие граждан в процессе и обслуживании государственного управления, открытость процесса государственного управления и предоставления государственных услуг, переход от общественно ориентированного управления к граждански ориентированному управлению и предоставлению услуг. Джоанна Брайсон, профессор этики и технологии в школе Херти (Берлин), утверждает, что на самом деле человечеству нужно решить только две проблемы: устойчивость и неравенство, или, говоря другими словами, безопасность и власть [16]. Она образно называет результат человеческой деятельности большим пирогом и задается вопросом: насколько большой пирог мы все вместе сможем испечь и, самое главное, насколько правильно мы его поделим, что такое «правильно» и как его нужно нарезать. Джоанна Брайсон считает уместным использовать подобную метафору, поскольку «... мы используем социальную безопасность, чтобы создавать общественные блага, которые приносят пользу всем. Тем не менее каждому человеку нужно достаточно пирога, чтобы процветать, и это проблема неравенства» [16].

Промышленность и экономические процессы в смарт-обществе характеризуются разработкой продуктов и услуг, которые выполняют автономную работу, функционируют с помощью технологий программирования и искусственного интеллекта; реализуют спрос и интерес граждан к промышленности и экономической деятельности. Одной из главных проблем современной экономики является эффективное использование ресурсов. Этот принцип требует сохранения и рационального использования возобновляемых ресурсов, а также сбалансирования темпов эксплуатации других ресурсов и темпов их регенерации. Smart society воплощает в реальность идею не только использования всех добываемых ресурсов, но и эффективное использование отходов в процессе переработки. Для обеспечения эффективного использования ресурсов необходимо использовать новые информационные технологии [17].

Производство знаний также сопряжено с активным участием простых граждан в производстве знаний, коллективного разума. Культурное развитие smart society подразумевает культивирование гармонизации различных стилей, отношений и ценностей жизни посредством недискриминационного обращения со всеми гражданами независимо от их религиозных конфессий, уровня образования, расовой принадлежности, возраста, материального положения, места проживания (речь идет не только о странах, 
но регионах, городах и отдельных улицах). Smart society создает условия для возможности выращивания культуры для поощрения инновационного и ориентированного на граждан образа жизни [18].

Исходя из идеи, что smart society нужно рассматривать как общество, которое прогрессивно использует потенциал цифровых технологий, можно выделить основные столпы smart society.

Smart society находится в постоянном взаимодействии, оно окутано невидимой паутиной, обладает мгновенно поступающей и распространяющейся информацией, поэтому connectivity - связность, способность к подключению - первый столп. Connectivity включает в себя мобильные, фиксированные, спутниковые и кабельные сети. Сеть является ключевым компонентом некоторых теорий построения обществ. Например, теория испанского социолога, профессора университета Южной Калифорнии Мануэля Кастельса [19].

Работы Мануэля Кастельса посвящены концептуализации сети в теории сетевого общества. Он рассматривает конфигурацию отношений между технологиями, экономикой и обществом, изложенную в opus magnum - одной из самых амбициозных работ ученого - «The Information Age trilogy - трилогия «Информационный век». Мануэль Кастельс представил сеть в качестве ключевой концепции макротеории, основной единицей анализа, которая объединяет социальные структуры, социальные действия, социальную организацию, пространство потоков и новые технологии в макротеоретическую структуру, которая использует квазимарксистские идеи, такие как информационный способ развития. Этим решением он способствовал более широкому принятию концепции сети как интерпретирующей нормы в социальных науках. Connectivity, по Кстельсу, - это ключевой фактор и компонент цепочки Machine-to-Machine (M2M) и возникающих в результате приложений и услуг, таких как электронное правительство, управление движением и безопасность дорожного движения [19].

Если есть как подключать, то нужно и что подключать. Умные устройства - это связанные между собой устройства, создаваемые smart society. Автомобили, светофоры и камеры, водяные насосы, электрические сети, бытовая техника, уличные фонари и мониторы здоровья - все это примеры вещей, которые должны стать умными. Эти устройства должны быть подключены к общим сетям таким образом, чтобы они могли обеспечить обществу возможность использования самых значительных достижений в области экономического и социального развития с учетом всевозрастающих потребностей умного общества.

Ни одно умное устройство не способно быть на службе у человека без использования специально разработанного программного обеспечения. Разработка программного обеспечения связывает и включает в себя первые два столпа, взаимодействие и синхронная работа которых поддерживают новые услуги, которые никогда не были бы возможны раньше. Эти новые услуги трансформируют все - от энергоэффективности до улучшения состояния окружающей среды, безопасности дорожного движения, продовольственной и водной безопасности, производства и основных государственных услуг.

Создание smart society зависит от степени развития цифровых технологий. Интеллектуальные технологии улучшают нашу жизнь тремя основными путями: в настоящее время практически все вещи или виды деятельности выполняются более эффективно и действенно, цифровые технологии изменяют нормы отношений, делают возможными новые типы отношений, расширяют и укрепляют наши связей друг с другом. Интернет оказывает большое влияние на то, как предприятия ведут бизнес и взаимодействуют 
друг с другом. Облачное хранилище данных, интегрированные системы закупок и «корпоративные социальные сети», которые облегчают общение внутри и между организациями в режиме реального времени, помогают странам улучшить жизнь своих граждан [20]. Таким образом, умные и цифровые технологии потенциально ведут к smart society. Искусственный интеллект (ИИ) и информационный век приносят нам больше информации о себе и друг о друге, чем когда-либо знало любое общество. В то же время это делает машины, казалось бы, более способными для любого человека, чем любой человек. Smart-технологии заставляют человека задуматься над множеством вопросов: каковы пределы ИИ? Разум и человечество шире? Каковы наши этические обязательства перед машинами? Они изменяют наши обязательства друг перед другом? Что лежит в основе наших социальных обязательств? Поиски ответов на эти вопросы также являются одной из движущих сил развития smart society.

\section{Мировые программы - практики по созданию smart society}

Планы по созданию smart society воплощаются в жизнь, например в Стратегии ИКТ (информационно-коммуникационные технологии, information communication technology - ICT) «Умная Япония», «Умный Таиланд 2020» и Инициативе «Умная Африка». Согласно отчетам этих стран по реализации развития плана создания smartsociety, smart- или умного общества, это общество или нация описываются как государство, в котором качество жизни граждан, эффективность, производительность и конкурентоспособность общества значительно улучшаются благодаря широкому использованию передовых ИКТ, таких как мобильные, сенсорные, искусственные технологии. Стремясь к созданию smart society, Инициатива «Умная Африка» провозгласила пять опор, которые необходимы для использования и внедрения передовых ИКТ: политика, доступ, электронное правительство, частный сектор / предпринимательство и устойчивое развитие. Эти столпы встроены в четыре сквозных инструмента, которые будут поддерживать внедрение Smart Africa. Эти факторы - инновации; связь и пропаганда; наращивание потенциала; мобилизация ресурсов [21].

Соединенное королевство Великобритании определяет следующие опоры, на которые должно опираться smart society: культура данных; уполномоченные, грамотные в цифровом отношении граждане; расширение прав и возможностей государственных учреждений, предлагающих разумное руководство; создание благоприятных инфраструктур; открытые платформы и рынки. Это то, на чем нужно сосредоточиться, чтобы максимально использовать возможности, которые дает следующая волна интеллектуального развития общества [1].

Статья Мэтью Глэддена «Who Will Be the Members of Society 5.0? Towards an Anthropology of Technologically Posthumanized Future Societies» посвящена вопросам трансформации общества Японии и усилиям японской науки и правительства на создание общества 5.0. [22]. Мэтью Гдэдден отмечает, что, по замыслу японского правительства и ученых, повседневная жизнь граждан будет улучшаться за счет все более тесного сотрудничества с искусственно интеллектуальными системами. Тем не менее очевидный парадокс лежит в основе усилий по созданию более «ориентированного на человека» общества, в котором люди будут жить вместе с разрастающимся массивом все более автономных социальных роботов. Исследование стремится проследить предполагаемую ориентированность на человека Общества 5.0. Различая «технологические» и «нетехнологические» процессы постгуманизации и применения феноменологической антропологической модели, Мэтью Глэдден демонстрирует как различные типы людей и нечеловеческих членов должны участвовать в Обществе 5.0. Описывает шесть кате- 
горий потенциальных людей и не людей, но членов Общества 5.0, и показывает, что все шесть имеют аналоги в более ранних обществах, что говорит о том, что социальный научный анализ прошлых обществ может пролить неожиданный свет на природу Общества 5.0 [22].

Японские ученые полагают, что в новом обществе, обществе 5.0, люди будут проявлять богатое воображение, чтобы определять различные потребности и проблемы, разбросанные по всему обществу, и сценарии их решения, а также творческие способности для реализации таких решений с использованием цифровых технологий и данных. Общество 5.0 будет воображаемым обществом, где цифровая трансформация объединяется с творчеством разных людей, что приводит к «решению проблем» и «созданию ценностей», которые приведут население всей планеты к устойчивому развитию. Это концепция, которая может способствовать достижению целей в области устойчивого развития, принятых Организацией Объединенных наций [23].

\section{Заключение}

Подводя итоги, опираясь на представленные в данной работе точки зрения o smart society, умное общество можно охарактеризовать как общество, успешно использующее потенциал цифровых технологий и подключенных устройств, а также цифровых сетей для улучшения жизни людей. Smart society является результатом современности и своеобразной «мечтой будущего» в силу бурного развития и повсеместного применения информационно-коммуникационных технологий. Интеграция сенсорных (встроенных в нас), коммуникационных и вычислительных достижений, сближающихся с нашими возросшими знаниями о человеческом восприятии, познании, поведении и физиологических функциях, вероятно, создаст это будущее. Однако для достижения этого устремленного состояния необходимо фундаментальное концептуальное переосмысление на различных уровнях. В новой реальности киберфизический мир будет сотрудничать и работать бок о бок с человеческим миром. Однако это будущее может быть жизнеспособным только с появлением новых смелых исследований, призванных катализировать междисциплинарные социальные и естественные науки и технику. Эта конвергенция необходима для формирования партнерских отношений между людьми и технологиями, которые обеспечивают устойчивый, динамичный, пригодный для жизни мир, ориентированный на людей. Мысль о том, что smart society - это общество, в котором люди, высокие технологии и природная окружающая среда будут объединены во множестве временных и пространственных масштабов, предвосхищает будущее, и человек пытается сконструировать новую модель общества, которая будет способна не только удовлетворять всевозрастающие потребности человека, но и способствовать процветанию в его дальнейшем развитии.

\section{СПИСОК ЛИТЕРАТУРЫ}

1. Creating the smart society: social and economic development through ICT applications. 6th Study Period 2014-2017. - Geneva, 2017. - 71 p. URL: https://www.itu.int/dms_pub/itu-d/opb/stg/D-STG-SG02.01.12017-PDF-E.pdf (дата обращения 15.05.2020).

2. Society // New World Encyclopedia. URL: https://www.newworldencyclopedia.org/entry/Society (дата обращения 20.05.2020).

3. Dean M. What is society? Social thought and the arts of government // British Journal of Sociology. 2010. - V. 61. - Iss. 4. - P. 678-695.

4. Ардашкин И. Б. Смарт-общество как этап развития новых технологий для общества или как новый этап социального развития (прогресса): к постановке проблемы // Вестник Томского государственного университета. Философия. Социология. Политология. - 2017. - № 38. - С. 32-45. 
5. Bächle T.C., Katzenbach C. Defining concepts of the digital society // The research of The Alexander von Humboldt Institute for Internet and Society (HIIG). - 2019. URL: https://www.hiig.de/en/project/conceptsof-digital-society (дата обращения 15.05.2020).

6. Haupt M. What is a Smart Society? Toward the transcendent model society of 2030. Project 2030. - 2019. URL: https://medium.com/project-2030/what-is-a-smart-society-92e4a256e852 (дата обращения 05.12.2019).

7. Chakravorti B., Chaturvedi R.S. The «smart society» of the future doesn't look like science fiction. - 2019. URL: https://hbr.org/2017/10/the-smart-society-of-the-future-doesnt-look-like-science-fiction (дата обращения 01.12.2019).

8. Hiroaki Nakanishi. Modern society has reached its limits. Society 5.0 will liberate us. World Economic Forum Annual Meeting. - 2019. - 256 p. URL: https://www.weforum.org/agenda/2019/01/modern-societyhas-reached-its-limits-society-5-0-will-liberate-us/ (дата обращения 05.12.2019).

9. Ferreira C.M., Serpa S. Society 5.0 and social development: contributions to a discussion // Management and Organizational Studies 5. - 2018. - V. 5. - Iss. 4. - P. 26-31. URL: http://www. sciedupress.com/journal/index.php/mos/article/view/14206/8970 (дата обращения 15.05.2020).

10. Medina-Borja A. Smart human-centered service systems of the future // Center for Research and Development Strategy Japan Science and Technology Agency. - 2017. - V. 5 - P. 235-239.

11. Arimoto T. Science advice and foresight under the complex and uncertain world. - September 29-30, 2016. URL: https://ec.europa.eu/info/sites/info/files/conferences/ingsa2016/day1_pls2_3_t_arimoto_ science_advice_and_foresight_under_the_complex_and_uncertain_world.pdf (дата обращения 20.05.2020).

12. Gladden M.E. Cyborgization and virtual worlds: portals to altered reality. - 2017 . Published by Mnemoclave. - 36 p. URL: www.matthewgladden.net/cyborgization-and-virtual-worlds/ (дата обращения 08.12.2019).

13. Как нам построить Smart-общество? // Наука и жизнь. URL: https://www.nkj.ru/news/21220/ (дата обращения 25.08.2020).

14. Самуйлов Г.Н. Философия Фрэнсиса Бэкона: наука и идеология // Вестник МГЛУ. Гуманитарные науки. - 2018. - Вып. 4 - С. 299-310.

15. Final Report. World Telecommunication Development Conference (WTDC) // Dubai World Trade Centre. 2014. URL: https://www.itu.int/en/ITU-D/TIES_Protected/WTDC14/WTDC14-FinalReport-E.pdf (дата обращения 20.05.2020).

16. Bryson J.J. The artificial intelligence of the ethics of artificial intelligence: an introductory overview for law and regulation. $\quad-\quad 2019, \quad$ July, $28 . \quad-\quad-37 \quad$ p. $\quad$ URL: http://www.cs.bath.ac.uk/ jjb/ftp/Bryson19AIforLawofAI.pdf (дата обращения 15.05.2020).

17. Bătăgan L. Methodologies for local development in smart society // Economics of Knowledge. - 2012. V. 4. - Iss. 3. - 3Q. - P. 23-34. URL: https://www.researchgate.net/publication (дата обращения 06.12.2019).

18. Matzner T., Ochs C. Privacy. Internet policy review // Journal on internet regulation. - 2019. - V. 8. Iss. 4. URL: https://policyreview.info/concepts/privacy (дата обращения 15.05.2020).

19. Ari-Veikko Anttiroiko. Networks in Manuel Castells' theory of the network society.- 2015, July, 16. URL: http://mpra.ub.uni-muenchen.de/65617 (дата обращения 15.05.2020).

20. Human enhancement and the future of work Report from a joint workshop hosted by the Academy of Medical Sciences, the British Academy, the Royal Academy of Engineering and the Royal Society. - 2012, November. - 72 p. URL: http://www.cs.bath.ac.uk/ jjb/ftp/Bryson19AIforLawofAI.pdf (дата обращения 20.05.2020).

21. BICS joins SMART Africa Alliance to implement the free roaming initiative on the continent. URL: https://bics.com/news/bics-joins-smart-africa-alliance-to-implement-the-free-roaming-initiative-on-thecontinent/ (дата обращения 27.08.2020).

22. Gladden M.E. Who will be the members of society 5.0? Towards an anthropology of technologically posthumanized future societies // Social Sciences, MDPI, Open Access Journal. - 2019. - V. 8. - P. 1-39. URL: https://ideas.repec.org/a/gam/jscscx/v8y2019i5p148-d230091.html (дата обращения 06.12.2019).

23. Yuko Harayama. Society 5.0: aiming for a new human-centered society. Japan's science and technology policies for addressing global social challenges // Hitachi Review. - 2018. V. - 66. - Iss. 6. - P. 558-559. URL: https://www.hitachi.com/rev/archive/2017/r2017_06/trends/index.html (дата обращения 20.05.2020).

Поступила 16.09.2020 г. 
UDC 316.325:004.738.5

\title{
SMART SOCIETY: APPROACHES AND INTERPRETATIONS
}

\author{
Maria V. Netesova ${ }^{1,2}$, \\ Netesova@tpu.ru \\ 1 Tomsk State Pedagogical University, \\ Russia, 634061, Tomsk, Kievskaya street, 60A \\ 2 National Research Tomsk Polytechnic University, \\ Russia, 634050, Tomsk, 30 Lenin avenue
}

Maria V. Netesova, senior teacher, Tomsk State Pedagogical University; postgraduate, National Research Tomsk Polytechnic University.

The relevance of the topic is hot and actual as the modern society is constantly transforming under the pressure of modern technologies usage. This opinion paper attempts to show key characteristics of the smart society concept. Smart society is an extremely recent concept as a guide for social development and that can have a profound impact on societies at all levels, such as in terms of the quality of life and sustainability. Aim. This paper investigates the factors that determine the «smart society» phenomenon. The work used a number of general scientific and philosophical research methods, including: logical-analytical (when building the logic of research), the method of theoretical analysis of literature on the topic with the possibility of logical and comparative analysis of the studied data, analytical and comparative methods, which made it possible to apply an interdisciplinary approach to the study of definitions «smart society» and «smartness» (rationality). Results. The interpretation of the «smart society» phenomenon is given. Definitions of «smart» and «society» are being developed. The concepts of foreign scientists such as Yuko Harayama (Japan), Thomas Christian Bächle (Germany), Tateo Arimoto (Germany), Mitchell Dean (USA), Matthew E. Gladden (Poland), Lorena Bătăgan (Turkey), Joanna J. Bryson (Germany), Alexandra Medina-Borja (Brazil), Ari-Veikko Anttiroiko (Finland) and other scientists whose research is in the field of various issues related to the development of smart society. This paper is based on very recent publications, but it also has a prospective component, which always generates some indeterminacy and uncertainty. Key characteristics of «smartness» (reasonableness) are identified, as well as the characteristics of the modern smart society directly, which relies on the power and potential of technology to make people more productive; to allow us focusing our resources on activities and relationships; to improve health, well-being and quality of life. The definition of "smartness» is considered in relation to each component of society (political sphere, public administration, services, economic activity, educational activity). Some kind of «driving forces» of smart society development are highlighted. The author has taken an attempt to present existing foreign programs («Smart Japan», «Smart Thailand 2020», Initiative «Smart Africa», «Smart UK»), the purpose of which is to create a smart society. The conclusion contains the main outputs on the presented topic.

Key words: Smart society, smart, society, smartness, rationality.

\section{REFERENCES}

1. Creating the smart society: social and economic development through ICT applications. $6^{\text {th }}$ Study Period 2014-2017. Geneva, 2017. 71 p. Available at: https://www.itu.int/dms_pub/itu-d/opb/stg/D-STGSG02.01.1-2017-PDF-E.pdf (accessed 15 May 2020).

2. Society. New World Encyclopedia. Available at: https://www.newworldencyclopedia.org/entry/Society (accessed 20 May 2020).

3. Dean M. What is society? Social thought and the arts of government. British Journal of Sociology, 2010, vol. 61, Iss. 4, pp. 678-695. 
4. Ardashkin I.B. Smart society as a stage of development of new technologies for society or as a new stage of social development (progress): to the problem statement. Tomsk State Pedagogical University Bulletin. Philosophy. Sociology. Politology, 2017, no. 38, pp. 32-45.

5. Bächle Th.Ch., Katzenbach Ch. Defining concepts of the digital society. The research of The Alexander von Humboldt Institute for Internet and Society (HIIG), 2019. Available at: https://www.hiig.de/en/project/concepts-of-digital-society (accessed 15 May 2020).

6. Haupt M. What is a Smart Society? Toward the transcendent model society of 2030. Project 2030. 2019. Available at: https://medium.com/project-2030/what-is-a-smart-society-92e4a256e852 (accessed 5 December 2019).

7. Bhaskar Chakravorti, Ravi Shankar Chaturvedi. The «Smart Society» of the future doesn't look like science fiction. 2019. Available at: https://hbr.org/2017/10/the-smart-society-of-the-future-doesnt-look-like-sciencefiction (accessed 1 December 2019).

8. Hiroaki Nakanishi. Modern society has reached its limits. Society 5.0 will liberate us. World Economic Forum Annual Meeting, 2019. 256 p. Available at: https://www.weforum.org/agenda/2019/01/modern-societyhas-reached-its-limits-society-5-0-will-liberate-us/ (accessed 5 December 2019).

9. Ferreira, Carlos M., Sandro S. Society 5.0 and social development: contributions to a discussion. Management and organizational studies 5, 2018, vol. 5, Iss. 4, pp. 26-31. Available at: http://www.sciedupress.com/journal/index.php/mos/article/view/14206/8970 (accessed 15.05.2020).

10. Medina-Borja A. Smart human-centered service systems of the future. Future Services \& Societal Systems in Society 5.0. Center for Research and Development Strategy Japan Science and Technology Agency. 2017. pp. 235-239. Available at: https://www.researchgate.net (accessed 25 May 2020).

11. Tateo Arimoto. Science advice and foresight under the complex and uncertain world. How can foresight \& horizon scanning better inform policy agendas? International Network for Government Science Advice. 2016. September 29-30. Available at: https://ec.europa.eu/info/sites/info/files/conferences/ingsa2016/ day1_pls2_3_t_arimoto_science_advice_and_foresight_under_the_complex_and_uncertain_world.pdf (accessed 20 May 2020).

12. Gladden M.E. Cyborgization and virtual worlds: portals to altered reality. Published by Mnemoclave. 2017. 36 p. Available at: www.matthewgladden.net/cyborgization-and-virtual-worlds/ (accessed 8 December 2019).

13. How do we build a Smart Society? Science and life. Available at: https://www.nkj.ru/news/21220/ (accessed 25 August 2020).

14. Samuylov G.N. The Philosophy of Francis Bacon: Science and Ideology. Bulletin of the Moscow State University. Humanities, 2018, Iss. 4, pp. 299-310.

15. Final Report. World Telecommunication Development Conference (WTDC). Dubai World Trade Centre. 2014. Available at: https://www.itu.int/en/ITU-D/TIES_Protected/WTDC14/WTDC14-FinalReport-E.pdf (accessed 20 May 2020).

16. Bryson J.J. The artificial intelligence of the ethics of artificial intelligence: an introductory overview for law and regulation. 2019, July, 28. 37 p. Available at: http://www.cs.bath.ac.uk/ jjb/ftp/Bryson19 AIforLawofAI.pdf (accessed 15 May 2020).

17. Bătăgan L. Methodologies for local development in smart society. Economics of Knowledge, 2012, vol. 4, Iss. 3, 3Q, pp. 23-34. Available at: https://www.researchgate.net/publication (accessed 6 December 2019).

18. Matzner T., Ochs C. Privacy. Internet Policy Review. Journal on internet regulation, 2019, vol. 8, Iss. 4. Available at: https://policyreview.info/concepts/privacy (accessed 15 May 2020).

19. Ari-Veikko Anttiroiko. Networks in Manuel Castells' theory of the network society. University of Tampere. 2015, July, 16. Available at: http://mpra.ub.uni-muenchen.de/65617 (accessed 15 May 2020).

20. Human enhancement and the future of work report from a joint workshop hosted by the Academy of Medical Sciences, the British Academy, the Royal Academy of Engineering and the Royal Society. 2012, November. 72 p. Available at: http://www.cs.bath.ac.uk/ jjb/ftp/Bryson19AIforLawofAI.pdf (accessed 20 May 2020).

21. BICS joins SMART Africa Alliance to implement the free roaming initiative on the continent. Available at: $\mathrm{https}$ ///bics.com/news/bics-joins-smart-africa-alliance-to-implement-the-free-roaming-initiative-on-thecontinent/ (accessed 27 August 2020).

22. Gladden M.E. Who will be the members of society 5.0? Towards an anthropology of technologically posthumanized future societies. Social Sciences, MDPI, Open Access Journal, 2019, vol. 8, pp. 1-39. Available at: https://ideas.repec.org/a/gam/jscscx/v8y2019i5p148-d230091.html (accessed 6 December 2019).

23. Yuko Harayama. Society 5.0: aiming for a new human-centered society. Japan's Science and Technology Policies for Addressing Global Social Challenges. Hitachi Review, 2018, vol. 66, Iss. 6, pp. 558-559. Available at: https://www.hitachi.com/rev/archive/2017/r2017_06/trends/index.html (accessed 20 May 2020). 